\title{
Consumo e digestibilidade aparente de rações com diferentes proporções de feno de capim Coastcross (Cynodon dactylon (L.) Pers.) \\ e soja crua moída e comportamento alimentar de ovinos
}

\author{
Intake and apparent digestibility of rations containing different \\ proportions of Coastcross (Cynodon dactylon (L.) Pers.) hay plus \\ ground soybean grain and sheep eating behaviour
}

\author{
Elaine de Fátima Leoni1'; José Antônio Fregonesi²; Ivone Yurika Mizubuti"; \\ Rafael Salmazo; ${ }^{3}$ Teresa Cristina Alves ${ }^{3}$; Tiago Rodrigues Casimiro ${ }^{3}$
}

Resumo

O objetivo deste trabalho foi determinar o consumo médio e a digestibilidade aparente dos nutrientes de rações contendo dois níveis de feno de capim coast-cross e soja crua moída, bem como estudar o comportamento de ovinos alimentados com essas rações. Foram utilizados dez ovinos machos, castrados, com peso vivo médio de $40,0 \mathrm{~kg}$, em delineamento experimental inteiramente casualizado com dois tratamentos $(\mathrm{T})(\mathrm{T} 1=80 \%$ de feno de coastcross picado $+20 \%$ de soja crua moída e $\mathrm{T} 2=60 \%$ de feno de coastcross picado $+40 \%$ de soja crua moída) e cinco repetições. Os tratamentos foram avaliados em regimes de consumo voluntário e consumo restrito. $\mathrm{O}$ ensaio compreendeu um período de adaptação de 15 dias, seguido de dois períodos de coleta de sete dias cada. A ração foi fornecida em duas refeições diárias, cada qual contendo a metade da quantidade de alimento a ser fornecido ao dia. Foram feitas observações etológicas durante 12 horas seguidas, nos três últimos dias do período de consumo voluntário, onde foram coletados dados de tempo de ingestão de ração, de ruminação e de repouso. A coleta de fezes foi efetuada duas vezes ao dia através das bolsas coletoras. Observou-se que não houve diferença $(\mathrm{P}>0,05)$ entre tratamentos para o consumo médio diário (CMD) de nutrientes pelos animais, com exceção da proteína bruta e extrato etéreo. Os coeficientes de digestibilidade aparente (CDA) da matéria seca (MS), fibra bruta (FB) e carboidratos totais (CT) foram maiores $(\mathrm{P}<0,05)$ nos animais submetidos ao consumo restrito. Não houve diferença na digestibilidade dos nutrientes estudados entre os tratamentos. O tempo despendido em alimentação e ruminação não foi influenciado pelo nível de concentrado da ração, mas o tempo despendido em ócio foi maior no tratamento com maior teor de concentrado. Pode-se concluir que os animais alimentados com $80 \%$ de feno de Coastcross e $20 \%$ de soja apresentaram maior CMD de PB e EE. Os CDA da MS, FB e CT das rações foram maiores em animais submetidos ao consumo restrito. O nível de.

Palavras-chave: Alimentação, avaliação de alimentos, ócio, ovinos, ruminação

\footnotetext{
1 Engenheira Agrônoma/UEL. E-mail: elaine.leoni@bol.com.br

2 Professores do Departamento de Zootecnia / CCA/ Universidade Estadual de Londrina. 2* Bolsista de produtividade do CNPq, E-mail: mizubuti@uel.br

3 Médicos Veterinários/ UEL.

* Autor para correspondência
} 


\begin{abstract}
The aims of this experiment were to determine the average daily intake (ADI) and the apparent digestibility coefficient (ADC) of rations containing two levels of coastcross hay and ground soybean grain, as well as, to study the behavior of sheep fed on these rations. Ten wethers averaging $40.0 \mathrm{~kg}$ of live weight were allocated in feeding trial cages for this experiment. A completely randomized design with two treatments $(\mathrm{T} 1=80 \%$ coastcross hay $+20 \%$ soybean grain and $\mathrm{T} 2=60 \%$ coast cross hay $+40 \%$ soybean grain) and five replicates, were used. The treatments were evaluated under two feeding systems (voluntary and restrict). There were two experimental periods of seven days with fifteen days of previous adaptation each. The animals were fed twice a day with rations containing half of the estimated daily intake. The behaviours studied were times spent eating, ruminating and resting in a five minutes interval observation during twelve hours. There were no significant differences $(\mathrm{P}>0.05)$ between treatments for nutrients ADI but for crude protein and ether extract (EE). The ADC for dry matter (DM), fiber (F) and total carbohydrates $(\mathrm{TC})$ were significantly greater $(\mathrm{P}<0.05)$ for the restrict than for voluntary feeding system. There were no significant differences between treatments for digestibility of the nutrients evaluated. There were no effects of rations with different levels of concentrated on animals' times spent eating and ruminating. However, time spent resting was significantly greater $(\mathrm{P}<0.05)$ for animals fed on rations containing higher levels of concentrate. In conclusion, sheep fed on $80 \%$ of coastcross hay plus $20 \%$ of ground soybean grain showed greater dry matter intake of CP and EE. The ADC for DM, F and TC were greater in restrict feeding systems. The concentrate level in the ration just affected the time spent in idle.
\end{abstract}

Key words: Idle, feeding, food evaluation, rumination, sheep

\section{Introdução}

$\mathrm{Na}$ prática de criação de ruminantes, a alimentação é responsável por 60 a $70 \%$ dos custos de produção para animais confinados. Os alimentos devem suprir as necessidades dos animais, explorando sua máxima capacidade digestiva, conseguindo, com isso, atingir o ápice de seu potencial genético para o aproveitamento da ração elaborada (DUTRA et al., 1997).

Em geral, as pastagens não suportam níveis produtivos intensos durante todo o ano em virtude das interações entre ambiente e manejo, podendo assim apresentar grande variação no seu valor nutritivo. A utilização de forragens conservadas, na forma de feno ou silagem, surge como alternativa para superar os problemas decorrentes de escassez de forragens. As forrageiras do gênero Cynodon apresentam potencial elevado de produção de forragem de boa qualidade, sendo usadas nas formas de pastejo e de feno (MOREIRA et al., 2001).

Entre os principais parâmetros relacionados com a qualidade das forrageiras, destacam-se o consumo alimentar e a digestibilidade. A forragem consumida determina a quantidade de nutrientes ingeridos e, consequentemente influencia os processos envolvidos na produção animal (Raymond apud MOREIRA et al., 2001). O consumo voluntário é a quantidade máxima de matéria seca que um animal espontaneamente ingere, enquanto a capacidade de um alimento ser ingerido depende da ação de vários fatores que interagem em diferentes situações de alimentação, comportamento e ambiente. Quando o volume da dieta é fator limitante, os animais não são capazes de ingerir quantidades suficientes de matéria seca para suprir suas necessidades energéticas, o que implica em menor produção (SIGNORETTI et al., 1999).

A digestibilidade do alimento é, basicamente, sua capacidade de permitir que o animal utilize, em maior ou menor escala, seus nutrientes. Essa capacidade é expressa pelo coeficiente de digestibilidade do nutriente, sendo uma característica do alimento e não do animal (SILVA; LEÃO, 1979).

A etologia assume caráter multidisciplinar, possibilitando a observação do animal de uma forma mais ampla e global, e desta forma, fornecendo critérios para se desenvolver e reavaliar técnicas criatórias capazes de propiciar o bem estar dos 
animais, e assim, melhorar substancialmente a eficiência produtiva do rebanho (POLLI et al.,1995).

O comportamento alimentar dos ruminantes pode ser caracterizado pela distribuição desuniforme de uma sucessão de períodos definitivos e discretos de atividades comumente classificadas como ingestão, ruminação e repouso. Geralmente, a ingestão ocorre de forma mais concentrada durante o dia (Dulphy e Faverdin apud FISCHER et al., 2000). Entretanto, as atividades ingestivas são ritmadas pela distribuição da ração, que estimula o animal a comer. Quando o alimento é distribuído duas vezes ao dia, as refeições que se seguem à distribuição do alimento são as mais importantes e duram de uma a três horas cada e os períodos de tempo gastos com a ingestão de alimentos são intercalados com um ou mais períodos de ruminação ou descanso. $\mathrm{O}$ tempo gasto para ruminar é mais elevado à noite, mas os períodos de ruminação são ritmados também pela distribuição dos alimentos (FISCHER et al.,1998).

A quantidade de alimento consumido por um ruminante em determinado período de tempo depende do número de refeições nesse período e da duração e taxa de alimentação de cada refeição. Esses processos resultam da interação do metabolismo do animal e das propriedades físicas e químicas da dieta, estimulando os receptores da saciedade (BÜRGER et al., 2000a). Um dos principais determinantes do desempenho animal é o consumo voluntário de alimento, e uma forma de se medir o valor do alimento para a produção animal é determinar a quantidade máxima de nutrientes digestíveis, que o animal ingeriria por unidade de alimento ofertado. Com base nesse valor, o nível ótimo de oferta pode ser determinado (DAMASCENO et al., 2000). Os mecanismos que controlam o consumo têm sido divididos em dois grupos principais: fisiológicos e físicos, atuando integralmente sobre o consumo. As atividades de ingestão são influenciadas pela distribuição dos alimentos, pois estimulam os animais a iniciarem ou continuarem uma refeição (FISCHER et al., 1997). Porém, a velocidade de alimentação de cada refeição está mais relacionada com o consumo de matéria seca do que com o número de refeições diárias (MIRANDA et al., 1999).

Segundo Van Soest (1994), o tempo de ruminação é influenciado pela natureza da dieta e parece ser proporcional ao teor de parede celular dos volumosos. Alimentos concentrados e fenos finamente triturados reduzem o tempo de ruminação, enquanto volumosos com alto teor de parede celular tendem a aumentar o tempo de ruminação. A descrição do comportamento alimentar e sua predição poderão contribuir para o entendimento das causas do início ou término das refeições e, desta forma, afetar o consumo voluntário dos animais (FISCHER et al., 2000).

O objetivo deste trabalho foi determinar a digestibilidade aparente dos nutrientes de rações a base de feno de capim coastcross contendo dois níveis de grãos de soja moídos, e estudar o comportamento alimentar de ovinos.

\section{Material e Métodos}

O ensaio de digestibilidade aparente, adotandose o método de coleta total de fezes, foi conduzido no Laboratório de Metabolismo Animal do Departamento de Zootecnia da Universidade Estadual de Londrina. Foram utilizados dez ovinos machos, castrados, com peso vivo médio de $40,0 \mathrm{~kg}$, distribuídos aleatoriamente em gaiolas metabólicas apropriadas, dotadas de cochos individuais para alimento, mistura mineral e bebedouro.

O delineamento experimental foi inteiramente casualizado com dois tratamentos $(\mathrm{T})$ e cinco repetições, sendo: $\mathrm{T} 1=80 \%$ de feno de coastcross picado $+20 \%$ de soja crua moída e $\mathrm{T} 2=60 \%$ de feno de coastcross picado $+40 \%$ de soja crua moída. Os tratamentos foram avaliados em regimes de consumo voluntário e consumo restrito.

O ensaio compreendeu um período de adaptação de 15 dias, seguido de dois períodos de coleta de sete dias cada. No período de adaptação foi determinado o consumo voluntário individual. No 
primeiro período de coleta, foi determinada a digestibilidade em condições de consumo voluntário e no segundo período em condições de consumo restrito. $\mathrm{O}$ consumo de ração foi calculado em função do tamanho metabólico ( $\mathrm{kg} \mathrm{PV}^{0,75}$ ), sendo que no regime de consumo restrito, este foi da ordem de
$75 \%$ do consumo obtido nos últimos três dias do período de adaptação.

As composições químicas dos ingredientes das rações experimentais, bem como as proporções desses ingredientes nas rações encontram-se na Tabela 1.

Tabela 1. Composição química dos ingredientes das rações e composição percentual das rações utilizadas nos tratamentos 1 e 2, com base na matéria seca.

\begin{tabular}{|c|c|c|c|c|}
\hline \multirow[t]{2}{*}{ Componentes } & \multirow{2}{*}{$\begin{array}{c}\text { Feno de } \\
\text { Coastcross }^{1}\end{array}$} & \multirow[t]{2}{*}{ Soja crua moída $^{1}$} & \multicolumn{2}{|c|}{ Tratamentos } \\
\hline & & & T1 & T2 \\
\hline Matéria seca $(\%)$ & 94,82 & 90,37 & 93,93 & 93,04 \\
\hline Matéria orgânica ${ }^{2}$ & 80,17 & 84,45 & 81,03 & 81,88 \\
\hline Proteína bruta $^{2}$ & 5,01 & 37,63 & 11,53 & 18,06 \\
\hline Extrato etéreo $^{2}$ & 0,62 & 14,60 & 3,42 & 6,21 \\
\hline Fibra bruta ${ }^{2}$ & 29,18 & 8,91 & 25,13 & 21,07 \\
\hline Carboidrato total $^{2}$ & 79,72 & 41,85 & 72,15 & 64,57 \\
\hline Cinzas $^{2}$ & 14,65 & 5,92 & 12,90 & 11,16 \\
\hline
\end{tabular}

Dados obtidos no laboratório de Nutrição animal do Departamento de Zootecnia/UEL. ${ }^{2} \%$ na matéria seca.T1= 80\% de feno de coastcross $+20 \%$ de soja crua moída e T2 $=60 \%$ de feno de coastcross $+40 \%$ de soja crua moída.

A ração foi fornecida em duas refeições diárias, às 7:00 e às 17:00 horas, cada qual contendo a metade da quantidade de alimento fornecido ao dia. Água e sal mineral foram fornecidos à vontade em cochos apropriados.

A coleta de fezes foi efetuada duas vezes ao dia através das bolsas coletoras, que permaneceram nos animais durante os períodos de consumo voluntário e restrito. As fezes foram pesadas diariamente e $20 \%$ do total excretado foram colocados em sacos plásticos e armazenados sob refrigeração para análise. Para as análises laboratoriais, as amostras diárias foram reunidas em amostras compostas/animal/tratamento e as determinações químicas de matéria seca (MS), proteína bruta (PB), extrato etéreo (EE) e fibra bruta (FB), foram realizadas conforme metodologias descritas por Association of Official Analytical Chemists. (1990a) e Association of Official Analytical Chemists (1990b). Os carboidratos totais (CT) foram obtidos através da equação $\mathrm{CT}(\%)=100$ -
$(\% \mathrm{~PB}+\% \mathrm{EE}+\% \mathrm{MM})$ e a matéria orgânica $(\mathrm{MO})$ através de $\mathrm{MO}=\mathrm{MS}-\mathrm{MM}$, sendo $\mathrm{MM}=$ matéria mineral.

Os coeficientes de digestibilidade dos nutrientes do feno de capim coast cross e da soja crua foram calculados através dos sistemas de equações citados por Silva e Leão (1979).

Foram feitas observações etológicas diretas (comer, deitar, em pé, ruminando e outras atividades, como, bebendo água ou ingerindo sal) durante 12 horas consecutivas, por três dias, a intervalos de 5 minutos. Considerou-se como refeição somente quando estas foram superiores a 30 minutos, sem intervalos de descanso (deitado) e ruminação.

A análise estatística dos dados foi realizada utilizando-se o programa STAT, sendo as médias comparadas pelo teste de Tukey a $5 \%$ de probabilidade. 


\section{Resultados e Discussão}

\section{Consumo médio diário}

Os valores obtidos para o consumo médio diário (CMD) dos nutrientes pelos animais, submetidos aos diferentes tratamentos e regimes de consumo alimentar, encontram-se na Tabela 2.

Como se esperava, houve um maior $(\mathrm{P}<0,05)$ consumo de todos os nutrientes estudados em animais submetidos ao regime de consumo voluntário devido à maior quantidade de alimento ingerido. Os valores de CMD de MS em animais submetidos ao consumo voluntário $(86,35 \mathrm{~g})$ estão acima dos valores citados pelo Agricultural and Food Research Council (1993) para ovinos pesando em média $40 \mathrm{~kg}$ de peso e ganho médio diário de 100 gramas ( $80 \mathrm{~g}$ de $\mathrm{MS} / \mathrm{kg}^{0,75}$ ).

Não houve interação entre tratamentos e regimes de consumo alimentar.
Observa-se que não houve diferença $(\mathrm{P}>0,05)$ entre tratamentos para o consumo médio diário (CMD) de nutrientes pelos animais, com exceção da proteína bruta e extrato etéreo. O CMD de PB e EE foi maior nos animais alimentados com a ração contendo $40 \%$ de soja crua, devido ao maior teor desses nutrientes na ração.

O CMD de MS, em g/kg PV ${ }^{0,75}$, para T1 $(59,35)$ e T2 $(68,88)$, foi maior do que os encontrados por Dias et al. (1999), que relataram valores de CMD de 50,02 e $59,56 \mathrm{~g}$ de $\mathrm{MS} / \mathrm{kgPV}^{0,75}$ de rações constituídas de feno de coastcross suplementados com farelo de soja e fubá de milho. Porém, os valores encontrados neste trabalho foram semelhantes aos apresentados por Tibo et al. (1999) e Cardoso et al. (2000) e menores do que os encontrados por Bürguer et al. (2000a) e Signoretti et al. (1999), os quais utilizaram $45 \%$ de concentrado na ração.

Tabela 2. Consumo médio diário (CMD) de matéria seca (MS), proteína bruta (PB), extrato etéreo (EE), fibra bruta (FB), matéria orgânica (MO) e carboidratos totais (CT) nos diferentes tratamentos e consumos alimentares.

\begin{tabular}{ccccccc}
\hline Tratamento & \multicolumn{7}{c}{ Consumo médio diário (g/kg PV $\mathbf{0}, 75 /$ dia) } \\
\cline { 2 - 7 } (T) & MS & PB & EE & FB & MO & CT \\
\hline 1 & $59,35 \mathrm{a}$ & $6,84 \mathrm{~b}$ & $2,03 \mathrm{~b}$ & $14,91 \mathrm{a}$ & $49,61 \mathrm{a}$ & $42,82 \mathrm{a}$ \\
2 & $68,88 \mathrm{a}$ & $12,44 \mathrm{a}$ & $4,28 \mathrm{a}$ & $14,51 \mathrm{a}$ & $56,99 \mathrm{a}$ & $44,48 \mathrm{a}$ \\
\hline Consumo & \multicolumn{7}{c}{} & & & \\
\hline Voluntário & $86,35 \mathrm{a}$ & $12,94 \mathrm{a}$ & $4,23 \mathrm{a}$ & $19,84 \mathrm{a}$ & $71,79 \mathrm{a}$ & $58,84 \mathrm{a}$ \\
Restrito & $41,88 \mathrm{~b}$ & $6,34 \mathrm{~b}$ & $2,08 \mathrm{~b}$ & $9,58 \mathrm{~b}$ & $34,81 \mathrm{~b}$ & $28,46 \mathrm{~b}$ \\
\hline C.V. (\%) & 10,54 & 12,90 & 10,60 & 4,27 & 9,81 & 3,51 \\
\hline
\end{tabular}

Médias seguidas de letras diferentes na coluna, diferem entre si $(\mathrm{P}<0,05)$ pelo teste de Tukey; $\mathrm{T} 1=80 \%$ de feno de coastcross $+20 \%$ de soja crua moída e $\mathrm{T} 2=60 \%$ de feno de coastcross $+40 \%$ de soja crua moída. CV: coeficiente de variação.

\section{Coeficiente de digestibilidade aparente}

Os coeficientes de digestibilidade aparente (CDA) da MS, PB, EE, FB, CT e MO nos diferentes tratamentos e regimes de consumos alimentares encontram-se na Tabela 3.

Não foram observadas diferenças $(\mathrm{P}>0,05)$ entre os valores de CDA da MS, EE, FB, MO, CT e PB entre tratamentos. Isto sugere que, na prática, não há necessidade de se utilizar mais do que $20 \%$ de grão de soja na ração de ovinos com o intuito de melhorar a utilização dos nutrientes da ração. Sugere também que até $40 \%$ de soja crua moída não prejudica a digestibilidade dos nutrientes, principalmente da fibra. Os CDA encontrados para os tratamentos 1 e 2 (Tabela 3) foram, de maneira geral, maior do que os relatados por Signoretti et al. (1999), Araújo et al. (1997), Tibo et al. (1997) e Tibo et al. (1999), Carvalho et al. (1997), Cardoso et al. 
(2000) e Dias et al. (1999), os quais utilizaram níveis de 25 e $37,5 \%$ de concentrado contendo farelo de soja + fubá de milho.

Não houve diferença $(\mathrm{P}>0,05)$ no $\mathrm{CDA}$ de $\mathrm{EE}$, $\mathrm{MO}$ e $\mathrm{PB}$ das rações quando avaliadas nos diferentes regimes de consumo alimentar (Tabela 3 ). Por outro lado, os CDA da MS, FB e CT foram maiores $(\mathrm{P}<0,05)$ no regime de consumo restrito. Isto demonstra que quando os alimentos são fornecidos em quantidades restritas ocorre maximização da digestão e maior eficiência de utilização dos nutrientes para atender as exigências dos animais.

Tabela 3. Coeficiente de digestibilidade aparente (CDA) da matéria seca (MS), extrato etéreo (EE), fibra bruta (FB), matéria orgânica $(\mathrm{MO})$, carboidratos totais $(\mathrm{CT})$ e proteína bruta $(\mathrm{PB})$ nos diferentes tratamentos e consumos alimentares

\begin{tabular}{ccccccc}
\hline Tratamento & \multicolumn{6}{c}{ Coeficiente de digestibilidade aparente (\%) } \\
\cline { 2 - 6 }$(\mathbf{T})$ & MS & EE & FB & MO & CT & PB \\
\hline 1 & $64,81 \mathrm{a}$ & $85,42 \mathrm{a}$ & $66,92 \mathrm{a}$ & $86,60 \mathrm{a}$ & $62,02 \mathrm{a}$ & $76,82 \mathrm{a}$ \\
2 & $65,09 \mathrm{a}$ & $89,40 \mathrm{a}$ & $64,80 \mathrm{a}$ & $89,61 \mathrm{a}$ & $59,60 \mathrm{a}$ & $80,73 \mathrm{a}$ \\
\hline Consumo & & & & & \\
\hline Voluntário & $59,29 \mathrm{~b}$ & $84,89 \mathrm{a}$ & $60,16 \mathrm{~b}$ & $86,65 \mathrm{a}$ & $55,49 \mathrm{~b}$ & $74,14 \mathrm{a}$ \\
Restrito & $70,61 \mathrm{a}$ & $89,29 \mathrm{a}$ & $71,56 \mathrm{a}$ & $89,55 \mathrm{a}$ & $66,13 \mathrm{a}$ & $83,40 \mathrm{a}$ \\
\hline C.V. (\%) & 12,44 & 4,09 & 12,24 & 5,52 & 12,40 & 8,59 \\
\hline
\end{tabular}

Médias seguidas de letras diferentes na coluna, diferem entre si $(\mathrm{P}<0,05)$ pelo teste de Tukey; $\mathrm{T} 1=80 \%$ de feno de coastcross $+20 \%$ de soja crua moída e $\mathrm{T} 2=60 \%$ de feno de coastcross $+40 \%$ de soja crua moída.

Mizubuti et al. (2002), trabalhando com feno de aveia e ervilha, também encontraram maior CDA da FB em animais mantidos sob regime de consumo alimentar restrito. Da mesma forma, Zeoula et al. (1994) observaram maior CDA de extrato nãonitrogenado e fibra bruta de ração à base de soja crua e feno de aveia nos animais sob regime de consumo restrito.

\section{Comportamento alimentar}

As características de comportamento alimentar dos animais, durante o período de consumo voluntário, estão apresentadas na Tabela 4. Não foram observadas diferenças significativas para os comportamentos de alimentação, ruminação e outras atividades. Entretanto, o tempo em que os animais ficaram em ócio foi maior $(\mathrm{P}<0,05)$ para aqueles submetidos ao tratamento com $40 \%$ de concentrado. Bürger et al. (2000b), trabalhando com bezerros holandeses, também verificaram um aumento no tempo de alimentação e ruminação com a diminuição do nível de concentrado da ração.

Dulphy, Remond e Theriez (1980) relataram que, aumentando-se a proporção de concentrado nas dietas, o tempo despendido em ruminação decresce e aumenta a eficiência de ruminação. Entretanto, este fato não aconteceu neste experimento. 
Tabela 4. Médias do tempo (min/12h) despendido em alimentação, ruminação, ócio e outras atividades dos animais submetidos aos diferentes tratamentos.

\begin{tabular}{cccc}
\hline & \multicolumn{3}{c}{ Tratamentos } \\
\hline Atividades (min/12 h.) & T1 & T2 & CV \\
\hline Alimentação & $207 \mathrm{a}$ & $195 \mathrm{a}$ & 9,54 \\
Ruminação & $202 \mathrm{a}$ & $195 \mathrm{a}$ & 11,17 \\
Ócio & $276 \mathrm{~b}$ & $291 \mathrm{a}$ & 11,33 \\
Outras & $31 \mathrm{a}$ & $29 \mathrm{a}$ & 3,32 \\
\hline
\end{tabular}

Médias seguidas de letras diferentes na mesma linha diferem entre si pelo teste de Tukey $(\mathrm{P}<0,05)$.

$\mathrm{T} 1=80 \%$ de feno de coastcross $+20 \%$ de soja crua moída e T2 $=60 \%$ de feno de coastcross $+40 \%$ de soja crua moída. Ócio: deitado ou em pé (não ruminando); outras atividades: bebendo água ou ingerindo sal. CV: Coeficiente de variação

Tabela 5. Média do número de refeições diárias ( $\mathrm{n}^{\circ} / 12$ h), duração das refeições principais (min/refeição), tempo de consumo $(\mathrm{min} / 12 \mathrm{~h})$ e taxa de consumo $(\mathrm{g} / \mathrm{min})$ nos tratamentos

\begin{tabular}{lccc}
\hline \multicolumn{3}{c}{ Tratamento } & $\mathrm{CV}$ \\
\hline Item & $\mathrm{T} 1$ & $\mathrm{~T} 2$ & 0,50 \\
$\mathrm{~N}^{\circ}$ de refeições diárias & $2,79 \mathrm{a}$ & $2,73 \mathrm{a}$ & 10,81 \\
Duração da refeição & $71,64 \mathrm{a}$ & $40,00 \mathrm{a}$ & 12,11 \\
Tempo de consumo & $160,00 \mathrm{a}$ & $104,00 \mathrm{~b}$ & 1,37 \\
Taxa de consumo & $3,14 \mathrm{a}$ & $3,67 \mathrm{a}$ & \\
\hline
\end{tabular}

Médias seguidas de letras diferentes na mesma linha diferem entre si pelo teste de Tukey $(\mathrm{P}<0,05)$. T1 $1=80 \%$ de feno de coastcross $+20 \%$ de soja crua moída e $\mathrm{T} 2=60 \%$ de feno de coastcross $+40 \%$ de soja crua moída. CV: Coeficiente de variação

O número de refeições diárias, a duração das refeições e a taxa de consumo não diferiram $(\mathrm{P}>0,05)$ entre os tratamentos (Tabela 5). Porém, o tempo despendido com as refeições principais foi menor $(\mathrm{P}<0,05)$ com o aumento do nível de concentrado na ração. Fischer et al. (1997), observando animais durante 24 horas, encontrou valores maiores para número de refeições diárias e tempo de consumo, porém, a média da duração das refeições foi menor do que as apresentadas neste trabalho.

\section{Conclusões}

O maior nível de soja na ração proporcionou um maior consumo médio diário de PB e EE pelos animais.
Os coeficientes de digestibilidade da MS, FB e $\mathrm{CT}$ das rações foram maiores em animais submetidos ao consumo restrito.

O nível de concentrado na ração não afetou o tempo total despendido em alimentação e ruminação, mas afetou o tempo despendido em ócio.

O aumento do nível de concentrado na ração não influenciou o número de refeições diárias, mas aumentou o tempo despendido com as refeições principais.

\section{Agradecimentos}

À Fazenda Experimental da Universidade Estadual de Londrina e ao Instituto Agronômico do Paraná pelo fornecimento do feno de capim 
Coastcross e grãos de soja, respectivamente. Ao Conselho Nacional de Desenvolvimento Cientifico e Tecnológico pela concessão de bolsa produtividade a Ivone Y. Mizubuti.

\section{Referências}

AGRICULTURAL AND FOOD RESEARCH COUNCIL. Energy and protein for ruminants. Wallinggford: UK.CAB INTERNATIONAL, 1993.

ARAÚJO, G. G. L.; SILVA, J. F. C.; VALADARES FILHO, S. C. V.; CAMPOS, O. F.; CASTRO, A. C. G.; SIGNORETTI, R. D.; TURCO, S. H. N.; HENRIQUES, L. T. Consumo e digestibilidade total dos nutrientes de dietas contendo diferentes níveis de volumosos em bezerros. In: REUNIÃO DA SOCIEDADE BRASILEIRA DE ZOOTECNIA, 34., 1997, Juiz de Fora. Anais... Juiz de Fora: Sociedade Brasileira de Zootecnia, 1997. p.345-357.

ASSOCIATION OF OFFICIAL ANALYTICAL CHEMISTS. Official Methods of Analysis. 15 ed. Arlington, Virgínia: Kenneth Helrich, 1990a. v.1, p.1- 684.

ASSOCIATION OF OFFICIAL ANALYTICAL CHEMISTS. Official Methods of Analysis. 15 ed. Arlington, Virgínia: Kenneth Helrich, 1990b. v.2, p.6851298.

BÜRGER, P. J.; PEREIRA, J. C.; QUEIROZ, A.C.; CECON, P. R.; MONTEIRO, H. C. F. Consumo e digestibilidade aparente total e parcial em bezerros holandeses alimentados com dietas contendo diferentes níveis de concentrado. Revista Brasileira de Zootecnia, Viçosa, v.29, n.1, p.206-214, jan./fev. 2000a.

BÜRGER, P. J.; PEREIRA, J. C.; QUEIROZ, A. C.; SILVA, J. F. C.; VALADARES FILHO, S. C.; CECON, P. R.; CASALI, A. D. P. Comportamento ingestivo em bezerros holandeses alimentados com dietas contendo diferentes níveis de concentrado. Revista Brasileira de Zootecnia, Viçosa, v.29, n.1, p.236-242, jan./fev. 2000b.

CARDOSO, R. C.; VALADARES FILHO, S. C.; SILVA, J. F. C.; PAULINO, M. F.; VALADARES, R. F. D.; CECON, P. R.; COSTA, M. A. L.; OLIVEIRA, R. V. Consumo e digestibilidades aparentes totais e parciais de rações contendo diferentes níveis de concentrado, em novilhos F1 Limousin e Nelore. Revista Brasileira de Zootecnia, Viçosa, v.29, n.6, p.1832-1843, nov./dez. 2000.

CARVALHO, A. V.; VALADARES FILHO, S. C.; SILVA, J. F. C.; QUEIROZ, A. C.; CECON, P. R.; MUNIZ, E. B. Níveis de concentrado em dietas de zebuínos 1. Consumo e digestibilidade aparente. Revista Brasileira de Zootecnia, Viçosa, v.26, n.5, p.986-995, set./out. 1997.
DAMASCENO, J. C.; SANTOS, G. T.; CECATO, U.; SAKAGUTI, E. S.; ALCALDE, C. R.; BRANCO, A. F. Consumo voluntário, digestibilidade e balanço de nitrogênio em ovinos recebendo palha de arroz amonizada em diferentes níveis de oferta. Revista Brasileira de Zootecnia, Viçosa, v.29, n.4, p.1167-1173, jul./ago. 2000.

DIAS, H. C. C.; VALADARES FILHO, S. C. V.; SILVA, J. F. C.; PAULINO, M. F.; CECON, P. R.; LEÃO, M. I. ; OLIVEIRA, R. V. ; COSTA, M. A. L. Consumo e digestão total em novilhos F1 Limousin X Nelore alimentados com cinco níveis de concentrado. In: REUNIÃO DA SOCIEDADE BRASILEIRA DE ZOOTECNIA, 36., 1999, Porto Alegre. Anais... Porto Alegre: Sociedade Brasileira de Zootecnia, 1999. p.274.

DULPHY, J. P.; REMOND, B.; THERIEZ, M. Ingestive behaviour and related activities in ruminants. In: RUCKEBUSH, Y.; THIVEND, P. (Eds.). Digestive physiology and metabolism in ruminants. Lancaster: MTP, 1980. p.103-122.

DUTRA, A. R.; QUEIROZ, A. C.; PEREIRA, J. C.; VALADARES FILHO, S. C.; THIÉBAUT, J. T. L.; MATOS, F. N.; RIBEIRO, C. V. M. Efeitos dos níveis de fibra e das fontes de proteína sobre o consumo e digestão dos nutrientes em novilhos. Revista Brasileira de Zootecnia, Viçosa, v.26, n.4, p.787-796, jul./ago. 1997.

FISCHER, V.; DESWYSEN, A. G.; DESPRES, L.; DUTILlEUL, P. A.; LOBATO, J. F. P. Comportamento ingestivo de ovinos recebendo dieta à base de feno durante um período de 6 meses. Revista Brasileira de Zootecnia, Viçosa, v.26, n.5, p.1032-1038, set./out. 1997.

FISCHER, V.; DESWYSEN, A. G.; DESPRES, L. et al. DUTILLEUL, P. A.; LOBATO, J. F. P. Padrões nectemerais do comportamento ingestivo de ovinos. Revista Brasileira de Zootecnia, Viçosa, v.27, n.2, p.362-369, mar/abr. 1998.

FISCHER, V.; DUTILLEUL, P.; DESWYSEN, A. G.; DĖSPRES, L.; LOBATO, J. F. P. Aplicação de probabilidades de transição de estado dependentes do tempo na análise quantitativa do comportamento ingestivo de ovinos. Revista Brasileira de Zootecnia, Viçosa, v.29, n.6, p.1811-1820, nov./dez. 2000.

MIRANDA, L. F.; QUEIROZ, A. C.; VALADARES FILHO, S. C.; CECON, P. R.; PEREIRA, E. S.; PAULINO, M. F.; LANA, R. P. Comportamento ingestivo de novilhas leiteiras alimentadas com dietas à base de cana-de-açúcar. Revista Brasileira de Zootecnia, Viçosa, v.28, n.3, p.614620, maio/jun. 1999.

MIZUBUTI, I. Y.; KHATOUNIAN, C. A.; RIBEIRO, E. L. A.; ROCHA, M. A.; SILVA, L. D. F.; MOURA FILHO, J.; PINTO, A. P.; FERNANDES, W. C. Consumo médio e digestibilidade aparente dos nutrientes do feno de aveia 
(Avena sativa L.) e ervilha (Pisum sativum L.) em ovinos submetidos a dois regimes alimentares. Revista Brasileira de Zootecnia, Viçosa, v.31, n.2, supl.2, p.1042-1049, mar/ abr., 2002.

MOREIRA, A. L.; PEREIRA, O. G.; GARCIA, R.; VALADARES FILHO, S. C.; CAMPOS, J. M. S.; MORAES, S. A.; ZERVOUDAKIS, J. T. Consumo e digestibilidade aparente dos nutrientes da silagem de milho e dos fenos de alfafa e de capim coast-cross em ovinos. Revista Brasileira de Zootecnia, Viçosa, v.30, n.3, supl.1, p.10991105, maio/jun. 2001.

POLLI, V. A.; RESTLE, J.; SENNA, D. B.; ROSA, C. E.; AGUIRRE, L. F.; DA SILVA, J. H. S. Comportamento de bovinos e bubalinos em regime de confinamento. Ciência Rural, Santa Maria, v.25, n.1, p.127-131, jan./fev. 1995.

SIGNORETTI, R. D.; SILVA, J. F. C.; VALADARES FILHO, S. C.; PEREIRA, J. C.; CECON, P. R.; QUEIROZ, A. C.; ARAUJO, G. G. L.; ASSIS, G. M. L Consumo e digestibilidade aparente em bezerros da raça holandesa alimentados com dietas contendo níveis diferentes de volumoso. Revista Brasileira de Zootecnia, Viçosa, v.28, n.1, p.169-177, jan./ fev. 1999.

SILVA, J. F. C.; LEÃO, M. I. Fundamentos de nutrição dos Ruminantes. Piracicaba: Livroceres, 1979.
TIBO, G. C.; VALADARES FILHO, S. C. V.; SILVA, J. F. C.; LEÃO, M. I. Consumo, digestibilidade e metodologias de coleta de amostra de digesta em novilhos alimentados com vários níveis de concentrado .In: REUNIÃO DA SOCIEDADE BRASILEIRA DE ZOOTECNIA, 34., 1997, Juiz de Fora. Anais... Juiz de Fora: Sociedade Brasileira de Zootecnia, 1997. p.137-139.

TIBO, G. C.; VALADARES FILHO, S. C. V.; SILVA, J. F. C. VALADARES, R. F. D.; PAULINO, M. F.; LEAO, M. I.; RENNÓ, L. N. Níveis de concentrado na dieta de novilhos F1 na dieta de novilhos F1 Simental X Nelore 1.Consumo e digestibilidade aparente total. In: REUNIÃO DA SOCIEDADE BRASILEIRA DE ZOOTECNIA, 36., 1999, Porto Alegre. Anais... Porto Alegre: Sociedade Brasileira de Zootecnia, 1999. p.286.

VAN SOEST, P. J. Nutritional ecology of the ruminant. 2.ed. Ithaca: Cornell, 1994.

ZEOULA, L. M.; BORGES, I.; BRANCO, A. F.; PRADO, I. N.; MOREIRA, H. L. M.; SANTOS, G. T.; SALINA, J. L.; MORAES, G. V. Valor nutritivo da soja crua em grão e do feno de aveia para ruminantes. Revista Unimar, Maringá, v.16, n.1, p.149-164, 1994. 